\title{
COLOQUIO "REFORMA Y EDUCACIÓN PÚBLICA: REFLEXIÓN Y DEBATE DESDE LA UNIVERSIDAD DE CHILE"
}

En la misma semana en que el Parlamento zanjó postura sobre el fin al lucro, la selección y el copago en la educación, algunas de las principales medidas contempladas en la Reforma Educacional impulsada por la Presidenta Michelle Bachelet, la Universidad de Chile organizó en su Casa Central un coloquio destinado específicamente a debatir sobre el alcance de esta reforma y sobre el rol que nos corresponde, en tanto la Universidad pública más antigua e importante del país, en el debate sobre la recuperación de la educación pública.

Con este fin, el de reunir a la comunidad académica y debatir sobre las diferentes visiones presentes al interior del plantel en materia de educación, la Vicerrectoría de Extensión y Comunicaciones decidió convocar a sus Premios Nacionales y académicos y académicas más destacados a reflexionar sobre las bases filosóficas y sociales de lo público en educación, en tanto la Universidad de Chile es parte fundante del sistema de educación pública y propone con fuerza su fortalecimiento a través de una política sostenida de apoyo a las instituciones estatales. Esta unidad propuso, desde el coloquio "Reforma y Educación Pública: Reflexión y debate desde la Universidad de Chile", potenciar la discusión sobre el sistema de educación superior, que ha adquirido enorme complejidad y en el que coexisten universidades de investigación, como la nuestra, con otras puramente docentes e institutos y centros de formación técnica de diversa índole y calidad.

Con una amplia asistencia y con las palabras inaugurales del Rector de la Universidad de Chile, Profesor Ennio Vivaldi, este coloquio abordó el tema planteado alrededor de cuatro mesas de debate que a continuación se reproducen tal como se realizaron el día 19 de agosto de 2014. Con esta actividad, la Universidad de Chile se posicionó como una voz de vanguardia en la discusión sobre lo público en el contexto de la Reforma Educacional y consolidó su rol como el principal plantel universitario del país y formador de profesionales e intelectuales con vocación pública. 